\title{
The role of benchmark technology in sustainable value analysis
}

Timo Kuosmanen ${ }^{1}$ and Natalia Kuosmanen ${ }^{1,2}$

1) MTT Taloustutkimus, Luutnantintie 13, 00410 Helsinki.

2) Department of Economics and Management, University of Helsinki, P.O. Box 27, 00014 University of Helsinki, Finland.

\begin{abstract}
Sustainable Value Analysis (SVA) [F. Figge, T. Hahn, Ecol. Econ. 48(2004) 173-187] is a method for measuring sustainability performance consistent with the constant capital rule and strong sustainability. SVA compares eco-efficiency of a firm relative to some benchmark. The choice of the benchmark implies some assumptions regarding the underlying production technology. This paper presents a rigorous examination of the role of benchmark technology in SVA. We show that Figge and Hahn's formula for calculating sustainable value implies a peculiar linear benchmark technology. We present a generalized formulation of sustainable value that is not restricted to any particular functional form and allows for estimating benchmark technology from empirical data. Our generalized SVA formulation reveals a direct link between SVA and frontier approaches to environmental performance measurement and facilitates statistical hypotheses testing concerning the benchmark.
\end{abstract}

\section{Keywords}

data envelopment analysis, eco-efficiency, opportunity cost, performance measurement, regression analysis, stochastic frontier analysis, sustainability. 


\section{Introduction}

Sustainability is a multidimensional concept that entails economic, environmental, and social aspects. Constanza et al. (1991) define sustainability as consumption that can continue indefinitely without degrading the capital stocks, including natural, physical, human, and intellectual capital. The notions of weak and strong sustainability can be distinguished according to the substitutability of different forms of capital. Weak sustainability allows for substitution between all forms of capital; any loss in one kind of capital can be substituted by a surplus in other. By contrast, strong sustainability assumes non-substitutability of at least some forms of capital, or requires a certain critical level which must be conserved to avoid irreversible losses.

Sustainable value analysis (SVA) developed by Figge and Hahn $(2004,2005)$ is a method for measuring corporate contributions to sustainability based on the constant capital rule and strong sustainability. A firm is said to create sustainable value whenever it uses its bundle of resources more efficiently than another firm would have used it. ${ }^{1}$ In principle, reallocating resources from firms that create negative sustainable value to firms that create positive sustainable value can increase the economic welfare while keeping all stocks of capital in the economy at a constant level. Thus, firms creating sustainable value would be able to compensate for any rebound effects that might occur.

In practice, sustainable value of a firm is measured by comparing eco-efficiency of the firm relative to the eco-efficiency of some benchmark. The specification of the benchmark involves at least three important choices:

- One common benchmark versus sector/firm specific benchmarks

- Ex ante imposed benchmark versus data driven benchmark

- Average practice benchmark versus best practice benchmark

Figge and Hahn $(2004,2005)$ advocate the use of a common, economy-wide benchmark that represents the average practice and is imposed a priori. Van Passel et al. (2007) have used sector specific benchmarks that are derived based on the average values in the data. Van Passel (2007) has applied best-practice benchmarks that are firm-specific and estimated from the data. All different approaches have their own merits as well as drawbacks. A common benchmark can be motivated by the fact that firms of different sectors compete for the same pool of resources in the economy, and thus performances of all firms should be assessed relative to one common performance target. In practice, however, SVA can only take into account some limited subset of resources (for which data exist), which may favor some sectors over others. Moreover, SVA does not take into account the price effects of reallocations, which can bias the value added figures used for calculating sustainable value. Estimating benchmarks from empirical data can result as more realistic performance targets, but the estimation process involves its own complications. Finally, average practice benchmarks are typically easy to identify, but outperforming the average is no guarantee of the optimal performance. The best practice benchmarks are more tedious to estimate, but they can provide firms with right incentives to continuously improve their performance and push the frontier further. ${ }^{2}$

The choice of this or that benchmark has always certain implications regarding the underlying production technology; the production function implied by the benchmark is here referred to as the benchmark technology. This paper presents a rigorous examination of the role of the benchmark technology in SVA. We show that Figge and Hahn's formula for calculating sustainable value implies a peculiar linear benchmark technology. We then present a generalized formulation of sustainable value that is not restricted to any particular functional form but allows for estimating benchmarks from empirical data. We show that our generalized formulation has an opportunity cost interpretation similar to the original SVA formula.

Our generalized SVA formulation has at least two types of methodological value. First, our formulation reveals a direct link between SVA and the frontier approach to environmental performance assessment (see e.g., Färe et al. 1996; Tyteca 1996, 1997; Callens and Tyteca 1999; Zaim

\footnotetext{
${ }^{1}$ By term "firm" we refer to any productive unit, which may be a private or public organization as well as an aggregated entity such as an industry, sector or country.

${ }^{2}$ Ansell et al. (2003) present an illuminating discussion about the different perspectives to benchmarking prevailing in the finance versus management literature.
} 
2004; Kuosmanen and Kortelainen 2005, 2007; Cherchye and Kuosmanen 2006; Coelli et al. 2007; and references therein). ${ }^{3,4}$

The rest of the paper is organized as follows. In the next section we formally introduce the SVA method. Then we recast SVA in terms of a more general benchmark technology. Final section presents some concluding remarks.

\section{Sustainable Value Added}

In this section we introduce SVA more formally. Consider a production process where R resources (including natural, physical, human, and intellectual capital) are transformed into economic output, measured in value added terms. The recourse use by firm $i$ is characterized by vector $\mathbf{x}_{i}=\left(x_{i 1} \ldots x_{i R}\right)^{\prime}$, and the value added of firm $i$ is denoted by $y_{i}$. According to Figge and Hahn $(2004,2005)$ (henceforth $\mathrm{FH}$ ), a firm creates sustainable value whenever it uses its bundle of resources more efficiently than another firm would have used it. Another firm used as a reference for comparison is referred to as benchmark; the value added and the resource use of the benchmark are denoted by $y^{*}$ and $\mathbf{x}^{*}=\left(x_{1}^{*} \ldots x_{R}^{*}\right)^{\prime}$, respectively. FH specify the benchmark values a priori (e.g., $y^{*}$ could be the GDP and the total use of resource $r$ in the economy); we consider the estimation of the benchmark in more detail in Sections 3 and 4. Given these notations, FH define firm $i$ 's sustainable value (SV) in using resource $r$ as

$$
S V_{i r}=\left(\frac{y_{i}}{x_{i r}}-\frac{y^{*}}{x_{r}^{*}}\right) x_{i r} .
$$

Note that expression (1) measures sustainable value in terms of a single resource $r$ only. Therefore, we will refer to (1) as partial sustainable value.

The rationale behind formulation (1) is the following. Ratio $y_{i} / x_{i r}$ can be interpreted as firm $i$ 's eco-efficiency in using resource $r$. Similarly, ratio $y^{*} / x_{r}^{*}$ can be seen as eco-efficiency of the benchmark. The expression within the brackets is referred to as value spread. If firm $i$ creates value added per unit of resource that is higher (lower) than the benchmark level, then the value spread is positive (negative). To convert this efficiency measure into a monetary figure, the value spread is multiplied by the total resource use $x_{\mathrm{ir}}$.

Most economic activities involve multiple resources. To measure sustainable value of firm $i$ in terms of its total resource use, FH simply take the arithmetic average of all partial sustainable values:

$$
S V_{i}=\frac{1}{R} \sum_{r=1}^{R} S V_{i r}
$$

Given data of firm $i$ and the benchmark, this sustainable value measure is easy to calculate; no estimation of any kind is required. However, expressions (1) and (2) are ill-defined whenever firm does not use one of the resources at all (i.e., $x_{i r}=0$ for some $r$ would imply division by zero in equation (1)). This can be a serious problem when a common economy-wide benchmark is applied across all sectors, because a typical firm does not use each and every resource available in the economy. Note that the zero values should not be simply omitted; firms deserve credit for not using a scarce resource that benefits the economy as a whole (and hence the benchmark).

To pave a way for the production function interpretation of the next section, we note that expression (2) can be harmlessly reorganized as

$$
S V_{i}=y_{i}-\frac{1}{R} \sum_{r=1}^{R}\left(\frac{y^{*}}{x_{r}^{*}}\right) x_{i r} .
$$

Note that formulation (3) remains well defined even when vector $x_{\mathrm{i}}$ contains zero elements; only the benchmark resource vector $x^{*}$ must be strictly positive. Expression (3) also provides some further

\footnotetext{
${ }^{3}$ See Fried et al (2007) for an up-to-date review of and introduction to the frontier estimation literature.

${ }^{4}$ The interface between the frontier approach and SVA has been first explored by Van Passel (2007), who has used bestpractice benchmarks estimated by stochastic frontier analysis method within the SVA framework. Our results establish a more direct connection between the two approaches.
} 
intuition to SVA: the sustainable value can be interpreted as the difference between firm i's value added and the weighted average of the eco-efficiency ratios of the benchmark. We can further rearrange (3) to the form

$$
S V_{i}=y_{i}-y^{*}\left[\frac{1}{R} \sum_{r=1}^{R}\left(\frac{x_{i r}}{x_{r}^{*}}\right)\right]=y_{i}-\frac{y^{*}}{D^{R}\left(\mathbf{x}_{i}, \mathbf{x}^{*}\right) R^{2}} .
$$

where $D^{R}\left(\mathbf{x}_{i}, \mathbf{x}^{*}\right)=\frac{1}{R} \sum_{r=1}^{R}\left(\frac{x_{r}^{*}}{x_{i r}}\right)$ is the Russell distance measure between vectors (introduced by Färe and Lovell 1978). Expression (4) reveals the alternative interpretation of sustainable value as the difference between the observed value added of firm $i$ and the benchmark value added, adjusted for the resource use by firm $i$.

\section{Production function interpretation of SVA}

In this section we recast SVA in terms of a general benchmark technology and examine its properties. Suppose the benchmark technology is characterized by a well-behaved production function $f: \mathbb{R}_{+}^{R} \rightarrow \mathbb{R}_{+}$. That is, for a given resource vector $\mathbf{x}$, the benchmark output is indicated by $f(\mathbf{x})$. Applying the analogous rationale as in equation (4), we interpret sustainable value as the difference

$$
S V_{i}=y_{i}-f\left(\mathbf{x}_{i}\right) \text {. }
$$

It is easy to verify that FH's formula (2) is the special case of (5) when the production function takes the linear form

$$
f(\mathbf{x})=\sum_{r=1}^{R} \beta_{r} x_{r},
$$

with fixed coefficients $\beta_{r}=\frac{y^{*}}{R x_{r}^{*}}$. Expression (6) reveals that FH's method is not free of assumptions about the production technology: in fact, hidden underneath is a rather peculiar assumption about linear production function, with the specific coefficients representing the eco-efficiency of the benchmark (multiplied by $1 / R$ ).

Now, let us take a closer look at the opportunity cost interpretation of SVA. FH interpret the ratio $y^{*} / x_{r}^{*}$ as the opportunity cost of resource $r$. This is a heroic assumption: it implies that a $z$ percent increase of resource $r$ while keeping all other resources at a constant level yields a $z$ percent increase in the value added. Clearly, this interpretation cannot hold simultaneously for all $R$ resources.

In terms of the benchmark technology $f$, the opportunity cost of using one unit of resource $r$ can be correctly expressed as the partial derivative $\frac{\partial f(\mathbf{x})}{\partial x_{r}}$, which indicates the marginal value product of resource $r$ in its alternative use. Note that, if we assume the particular linear function of expression (6), the opportunity cost of resource $r$ is actually $\beta_{r}=\frac{y^{*}}{R x_{r}^{*}}$, not $y^{*} / x_{r}^{*}$. In fact, the linear structure of FH's benchmark technology is a direct result of the strong assumption about the opportunity cost.

We can exploit the previous idea further and derive our generalized sustainable value formula (5) from FH's original proposal by means of the opportunity cost $\frac{\partial f(\mathbf{x})}{\partial x_{r}}$. Inserting this opportunity cost (multiplied by $R$ as in FH's formula) to the partial sustainable value (1), we obtain

$$
S V_{i r}=\left(\frac{y_{i}}{x_{i r}}-R \cdot \frac{\partial f\left(\mathbf{x}_{i}\right)}{\partial x_{r}}\right) x_{i r} .
$$

Thus, the total sustainable value (2) becomes

$$
S V_{i}=\frac{1}{R} \sum_{r=1}^{R}\left(\frac{y_{i}}{x_{i r}}-R \cdot \frac{\partial f\left(\mathbf{x}_{i}\right)}{\partial x_{r}}\right) x_{i r} .
$$

Rearranging expression (8) similar to (3), we obtain 


$$
S V_{i}=y_{i}-\sum_{r=1}^{R} \frac{\partial f\left(\mathbf{x}_{i}\right)}{\partial x_{r}} x_{i r}
$$

By Taylor's theorem, $\sum_{r=1}^{R} \frac{\partial f\left(\mathbf{x}_{i}\right)}{\partial x_{r}} x_{i r} \cong f\left(\mathbf{x}_{i}\right)$, which reveals that equation (9) can be seen as the first order Taylor series approximation of (5). Thus, we have shown that formula (5) has an analogous opportunity cost interpretation as the original FH formulations (1) and (2).

Thus far we have considered sustainable value in absolute scale, measured in currency units. Relative efficiency measures, expressed in percentage terms, can provide valuable complementary information. FH (2005) have introduced the notion of sustainable efficiency, defined as the ratio:

$$
S E_{i}=\frac{y_{i}}{y_{i}-S V_{i}} .
$$

If the sustainable efficiency takes a value greater (less) than one (100\%), then firm $i$ is more (less) efficient than the benchmark. Applying our production function interpretation (5), we can rephrase equation (10) as

$$
S E_{i}=\frac{y_{i}}{y_{i}-\left(y_{i}-f\left(\mathbf{x}_{i}\right)\right)}=\frac{y_{i}}{f\left(\mathbf{x}_{i}\right)} .
$$

Thus, sustainable efficiency can be interpreted as the ratio of the observed and the benchmark outputs. Interestingly, in the present single-output case, sustainable efficiency is equivalent to the classic Shephard (1953) output distance function and the Farrell (1957) output efficiency measure. From purely technical perspective there is little new in sustainable efficiency: this performance metric has been known in the field of productive efficiency analysis for more than five decades.

\section{Conclusions}

We have considered the role of the benchmark technology in SVA from different perspectives. We first showed that Figge and Hahn's $(2004,2005)$ formulation for sustainable value implies a peculiar linear benchmark technology. We therefore presented a generalized formulation of sustainable value that is consistent with nonlinear benchmark technologies and facilitates estimation of the benchmarks from empirical data.

\section{References}

Ansell, J., Moles, P. and Smart, A. 2003. Does benchmarking help? International Transactions in Operational Research 10, 339-350.

Callens, I. and Tyteca, D. 1999. Towards indicators of sustainable development for firms: a productive efficiency perspective, Ecological Economics 28(1), 41-53.

Cherchye, L. and Kuosmanen, T. 2006. Benchmarking Sustainable Development: A Synthetic Meta-Index Approach, Ch. 7 in M. McGillivray and M. Clarke (Eds.): Understanding Human Well-being, United Nations University Press, Tokyo.

Coelli, T., Lauwers, L. and Van Huylenbroeck, G. 2007. Environmental efficiency measurement and the materials balance condition, Journal of Productivity Analysis, to appear.

Constanza, R., Daly, H.E. and Barholomew, J.A. 1991. Goals, agenda, and policy recommendations for ecological economics. In: R. Constanza (Ed.), Ecological Economics: The Science and Management of Sustainability. Columbia University Press, 1-20.

Färe, R. and Lovell, C.A.K. 1978. Measuring the technical efficiency of production, Journal of Economic Theory 19(1), 150-162.

Färe, R., S. Grosskopf and Tyteca, D. 1996. An activity analysis model of the environmental performance of firms: Application to fossil-fuel-fired electric utilities, Ecological Economics 18(2), 161-175. 
Farrell, M.J. 1957. The measurement of productive efficiency, Journal of the Royal Statistical Society, Series A 120 (3), 253-281.

Figge, F. and Hahn, T. 2004. Sustainable value added - measuring corporate contributions to sustainability beyond eco-efficiency, Ecological Economics 48(2), 173-187.

Figge, F. and Hahn, T. 2005. The cost of sustainability capital and the creation of sustainable value by companies, Journal of Industrial Ecology 9(4), 47-58.

Fried, H., Lovell, C.A.K. and Schmidt, S. 2007. The measurement of productive efficiency and productivity change, Oxford University Press, New York.

Kuosmanen, T. and Kortelainen, M. 2005. Measuring Eco-efficiency of Production with Data Envelopment Analysis, Journal of Industrial Ecology 9(4), 59-72.

Kuosmanen, T. and Kortelainen, M. 2007. Valuing environmental factors in cost-benefit analysis using data envelopment analysis, Ecological Economics 62(1), 56-65.

Shephard, R. W. 1953. Cost and production functions, Princeton University Press, Princeton, N.J.

Tyteca, D. 1996. On the measurement of the environmental performance of firms - A literature review and a productive efficiency perspective, Journal of Environmental Management 46, 281-308.

Tyteca, D. 1997. Linear programming models for the measurement of environmental performance of firms Concepts and empirical analysis, Journal of Productivity Analysis 8, 183-197.

Van Passel, S. 2007. Benchmarking sustainability assessment, unpublished manuscript.

Van Passel, S., Nevens, F., Mathijs, E. and Van Huylenbroeck, G. 2007. Measuring farm sustainability and explaining differences in sustainable efficiency, Ecological Economics 62(1), 149-161.

Zaim, O. 2004. Measuring environmental performance of state manufacturing through changes in pollution intensities: a DEA framework, Ecological Economics 48(1), 37-47. 